\title{
XXIX. On the changes in length produced in iron wires by magnetization
}

\section{Louis Trenchard More Ph.D.}

To cite this article: Louis Trenchard More Ph.D. (1895) XXIX. On the changes in length produced in iron wires by magnetization, Philosophical Magazine Series 5, 40:245, 345-361, DOI: $10.1080 / 14786449508620779$

To link to this article: http://dx.doi.org/10.1080/14786449508620779

曲 Published online: 08 May 2009.

Submit your article to this journal $\widetilde{x}$

Џ Article views: 2

Q View related articles $\asymp$ 
Changes in Length in Iron Wires by Magnetization. 345

The question then arises, whether this last relation is direct, or arises from some material property changing with the temperature? Is it possible that the velocity of light may vary with temperature, apart from any relation to material substances, or is the foregoing relationship dependent upon some molecular function like that suggested, that is "molecular domain?"

It seems impossible to answer the first part of this question. The second part can be judged by analogy, which would appear to suggest that a molecular function is more probable. Thus, one might expect that the linetic energy of the particles is the property directly increased by rise of temperature, and that many or all other properties of the molecule are consequential upon that. The apparent volume of course increases. That fraction of the volume which is measured by

$$
\frac{\mu^{2}-1}{\mu^{2}+2} v \text {, or } \frac{\mu-1}{\mu}(v-\beta)
$$

also increases, whatever it may be called. This constant fact appears to be a decided argument in favour of these expressions, giving "domain " and not "volume of matter" simply. But again, if the plea for "domain" be granted, there ought to be increase, not only when the liquid is heated, but also when it is changed into a vapour. This is actually the case for $\frac{\mu-1}{\mu}(v-\beta)$, the value of which increases in the ratio 1 to 1.4 or 1.5 . This variability may be compared with that found by van der Waals for his constant $b$ " "Continuity \&c.”, Phys. Soc. translation, p. 409).

XXIX. On the Changes in Length produced in Iron Wires by Magnetization. By Louis Trenchard More, Ph.D., Johns Hopkins University*.

THIS investigation was undertaken at the suggestion of 1 Professor Rowland, and has for its object the finding of a relation between the change of length produced in iron wires by magnetization and the intensity of magnetization existing in the wire. It was hoped thus to obtain results that would be comparable and to avoid certain errors common to all previous work.

* Communicated by the Author. 


\section{Historical.}

That magnetizing an iron rod causes it to alter its length was first discussed by Joule* in 1847. His attention was called to the phenomenon by a machinist of Manchester, who imagined that the volume of a mass of iron was increased by magnetizing it. Joule, to test the opinion of the machinist, immersed a mass of iron in a closed vessel full of water in which stood a fine capillary tube. When the iron was strongly magnetized the height of the column of water in the tube remained unaltered, showing that within the limits of accuracy of his apparatus, for the intensity employed, the volume of the iron was unchanged. Bidwell $\dagger$ has also investigated this subject and found, on the contrary, that the volume was affected by magnetization. The volume diminishes at first and attains a minimum. It then increases, until with sufficiently intense fields the original size is regained. After reaching this point the volume continues to increase. As a consequence of this relation, if Joule had used an intensity either greater or less, he probably would have noticed a change in the volume. Joule afterwards, by means of a system of levers, found that the length of a rod was increased by the magnetizing force, and gave as a result of his observations the following laws:-

1st. When soft iron rods are magnetized their length is increased, and the elongation is approximately proportional to the square of the magnetizing force.

2nd. Tension applied to the rod diminishes the elongating effect, and "In the case of a bar one foot long and one-quarter inch in diameter, a tensile force of about 600 pounds caused all the phenomena of changes of length to disappear."

3rd. "That the elongation is, for the same intensity of magnetism, greater in proportion to the softness of the metal. It is greatest of all in the well-annealed iron bars, and least in hardened sieel. This circumstance appears to me to favour the hypothesis that the phenomena are produced by the attractions taking place between the magnetized particles of the bar; an bypothesis in perfect accordance with the law which I have pointed out," that the elongation was proportional to the square of the intensity of magnetization.

The first two laws pointed out by Joule have been often confirmed, but the third seems to rest on a single experiment, and until very recently there have been no published records,

* Phil. Mag. [3] vol. xxx. pp. 76 \& 225.

$\uparrow$ Proc. Roy. Soc. vol. lvi. p. 94. 
that I have seen, bearing on the result found by Joule. Shelford Bidwell*, while investigating the subject, obtained results the converse of Joule's,--indicating that not only hardening but also annealing the iron diminished the elongating effect. He mentions one specimen that, when annealed, contracted in length instead of elongating upon the application of the feeblest magnetizing force.

Barrett $\uparrow$ in 1870 discovered that nickel, when magnetized, contracts instead of elongating. Three years later A. M. Mayer $\ddagger$ published an account of his experiments on this subject. His results, in the main, verified Joule's observations, with the exception of the action of hard steel. This discrepancy was shown some years later by Bidwell to follow from their different methods of experimenting. Joule applied a current of the same intensity but once, and both on making and breaking the circuit observed an elongation; while Mayer used specimens already permanently magnetized, and on observing the temporary magnetization found a contraction on making circuit and an elongation on breaking it.

Mayer also observed hysteretic effects ; that is, the elongation due to a magnetizing force was less if the force had been reached by successively increasing values than it was if the current had been decreased from a maximum: the rod remaining slightly elongated after the magnetizing force had been removed : an effect analogous to the lagging of the induction behind the magnetizing force. Nagaoka $\S$ has discussed this phenomenon in the article cited, and has obtained complicated curves showing the complete cycle of the hysteretic phenomena for both iron and nickel.

The experiments mentioned were limited to comparatively feeble fields. The work of finding the effects due to intense fields has been most thoroughly done by Shelford Bidwell Il, who has found that rods do not continue to elongate indefinitely with increasing strengths of field as the other investigators supposed, but that a maximum value is after a time reached. The rod then begins to shorten, and very intense fields produce an absolute contraction which approaches a limiting value asymptotically. He also experimented with rings of iron, and with rods of steel, nickel, manganese steel, cobalt, and bismuth.

* Proc. Roy. Soc. vol. lv. p. 228.

+ 'Nature,' 1882.

† Phil. Mag. [4] vol. xlvi. p. 179.

$\S$ Phil. Mag. [5] vol. xxxvii. p. 181.

il Proc. Roy. Soc. vol. xxxriii. p. 265 ; vol. xl. pp. 109 \& 237 ; vol. xlvii. p. 469 ; vol. lv. p. 228 ; Trans. Roy. Soc. vol. clxxix. (A), p. ¿05. 
Investigations upon this subject have also been made by Berget*, Nagaoka $\uparrow$, Lochner $\ddagger$, Jones $\S$, and Bock $\|$.

For convenience I have collected in a summary the results obtained by the different observers.

\section{Soft Iron.}

Soft iron elongates when magnetized. The elongation attains a maximum, and then diminishes with increasing strength of field until a state is reached when the rod returns to its original length. Further increase of field causes the rod to contract.

There is no minimum length, the rod approaching asymptotically a limiting value.

For a given strength of field, both hardening and annealing diminish the elongation and increase the contraction shown by the rod before it was subjected to these operations (Bid well).

Tension also diminishes the elongation and increases the contraction of the rod.

For a sufficiently great tension no elongation occurs, the rod coutracting upon the application of the smallest magnetizing forces.

For a given length, the effects both of elongation and of contraction are greater for thin than for thick rods (Bidwell).

S. J. Lochner I comes to the conclusion from his own experiments that the converse is true-that thick bars give greater expansion than thin ones.

Very little reliance can be put in these last experiments, and the dependence of the change of length upon the ratio of the length to the diameter cannot be inferred from them. Bidwell used three rods, 10 centimetres long and $2 \cdot 65,3 \cdot 65$, and 6.25 millimetres in diameter, and assumed them to be of iron of similar composition. It is well known that different specimens of iron, apparently similar in structure, give results that vary 25 per cent. and more. So that the small variations in the change of length noted by him cannot safely be said to be due to the differences in their diameters, especially as he made no determination of the permeability. Lochner avoided this error by testing an iron rod, and then, after having cut off a portion, testing it again. $\mathrm{He}$, however, took no precautions to have the field uniform. His solenoid was nearly

* Compt. Rend. tom. cxv. p. 722.

+ Wied. Ann. liii. pp. 481 \& 487 (1894).

I Phil. Mag. vol. xxxvi. p. 504 (1893).

$\S$ Phil. Mag. vol. xxxix. p. 254 (1895).

\|I Wied. Ann. 1895.

I) Lochner, loc cit. 
four times as long as the shortest rod used, and the ratio of the diameter to the length of the rod was only 1 to 32 . Besides the uncertainties introduced by such a poor arrangement for a uniform field, great errors would be produced by the strong poles created at the ends of the rod.

\section{Object of Experiment.}

A careful study of the results obtained for iron by the different observers will show that although the general appearance of their curves is very similar, yet their absolute values vary widely, two specimens often having maximum elongations that differ 20 or 30 per cent. There is, unfortunately, no way of comparing these results, for it has been the custom to use as coordinates the change of length and the intensity of the external field. For a given apparatus this intensity depends only on the current used, and not at all on the specimen to be examined. The elongation is dependent upon the intensity of magnetization in the wire, and this is the quantity that varies with the specimen employed. For that reason the relation should be found. between these two quantities.

It is of course essential to have the rod uniformly magnetized throughout its length; that is, the field should be uniform and there should be no free poles. These conditions may be best obtained in one of two ways : either by having the metal in the shape of a ring and observing the change in diameter of the ring when magnetized by a solenoid wound upon it, or by using long wires of the metal. In the second case only the middle part of the wire should be observed, and the solenoid used to magnetize it should be considerably longer than the portion of the wire experimented upon. In this investigation the latter method was chosen, as rings are less convenient and also because it was desirable to observe the effects of tension in the metal.

When a rod of iron is magnetized, the change in length observed is due to several causes-three at least; and to obtain a correct idea of the phenomena these causes and their effects should be separated. There is, first, the direct action of the magnetism, and this may possibly be due to the orienting of the magnetized particles of the rod. Secondly, there are indirect actions of the magnetism which tend to change the length of the rod. These indirect actions are the mechanical stresses created in the rod by the magnetism. The first of these mechanical stresses is the tractive force of the magnet, and is measured by $\mathrm{B}^{2} / 8 \pi$. That this force exists, tending always to contract the rod, is seen from the fact that 
if the magnet is cut in two the ends are held together by a force $\mathrm{B}^{2} / 8 \pi$ per square centimetre, showing that this force must always be present when a rod is magnetized. The agreement between the theoretical value $\mathrm{B}^{2} / 8 \pi$ and the experimental law for the lifting-power has been recently shown by E. Taylor Jones*. This effect for high intensities of magnetization is a large one, and becomes one of the most important factors in the observed changes in length. The second of these mechanical stresses is the effect due to the change in Young's Modulus when the rod is magnetized. That the elasticity is influenced by magnetization was shown theoretically by J. J. Thomson $t$, and the phenomenon was observed last year in some experiments made by the writer; but no quantitative results could be obtained beyond the fact that the elasticity for soft iron was slightly diminished. A. Bock concludes from his work that the decrease in elasticity must be less than one-half per cent. If the wire is not stretched by weights, this decrease in the elasticity will affect only the contraction due to the $\mathrm{B}^{2} / 8 \pi$ force. This decrease in the elasticity, according to Bock, is very small and less than onehalf per cent. On the other hand, if the wire is loaded with weights this effect becomes very marked since a large quantity, the stretch of the wire by the great weight, is altered. This question will be more fully discussed later in the paper.

If these two indirect actions were allowed for, there would remain only the direct action of the magnetism upon the metal under a constant tension. This latter relation would evidently furnish comparable results, and may in the future throw some light upon the action of magnetism on matter.

\section{Apparatus.}

Since it was necessary to obtain the modulus of elasticity for the specimen experimented on, in order to make a proper correction for the electromagnetic stress, and as I wished to observe the effects of mechanical stress, it was convenient to experiment on thin long wires of the metal placed in a vertical position. To magnify the phenomena, a system of levers was used involving the tilting of a mirror mounted on three legs very close together; a method first invented by Professor Rowland. The general plan of using lever's and a jacket cylinder was suggested to me by Dr. Ames.

The wire to be tested was suspended from a tall tripod

* Jones, loc, cit.

$\dagger$ 'Application of Dynamics to Physics and Chemistry,' p. 58.

f Bock, loc. cit. 
standing on a stone slab that rested on two brick piers. A hole was cut in the slab so that the wire could be passed through it, and the free end permitted to almost reach the floor of the room. A hollow brass cylinder 1.6 centim. in diameter and about 68 centim. long (fig. 1) was screwed to
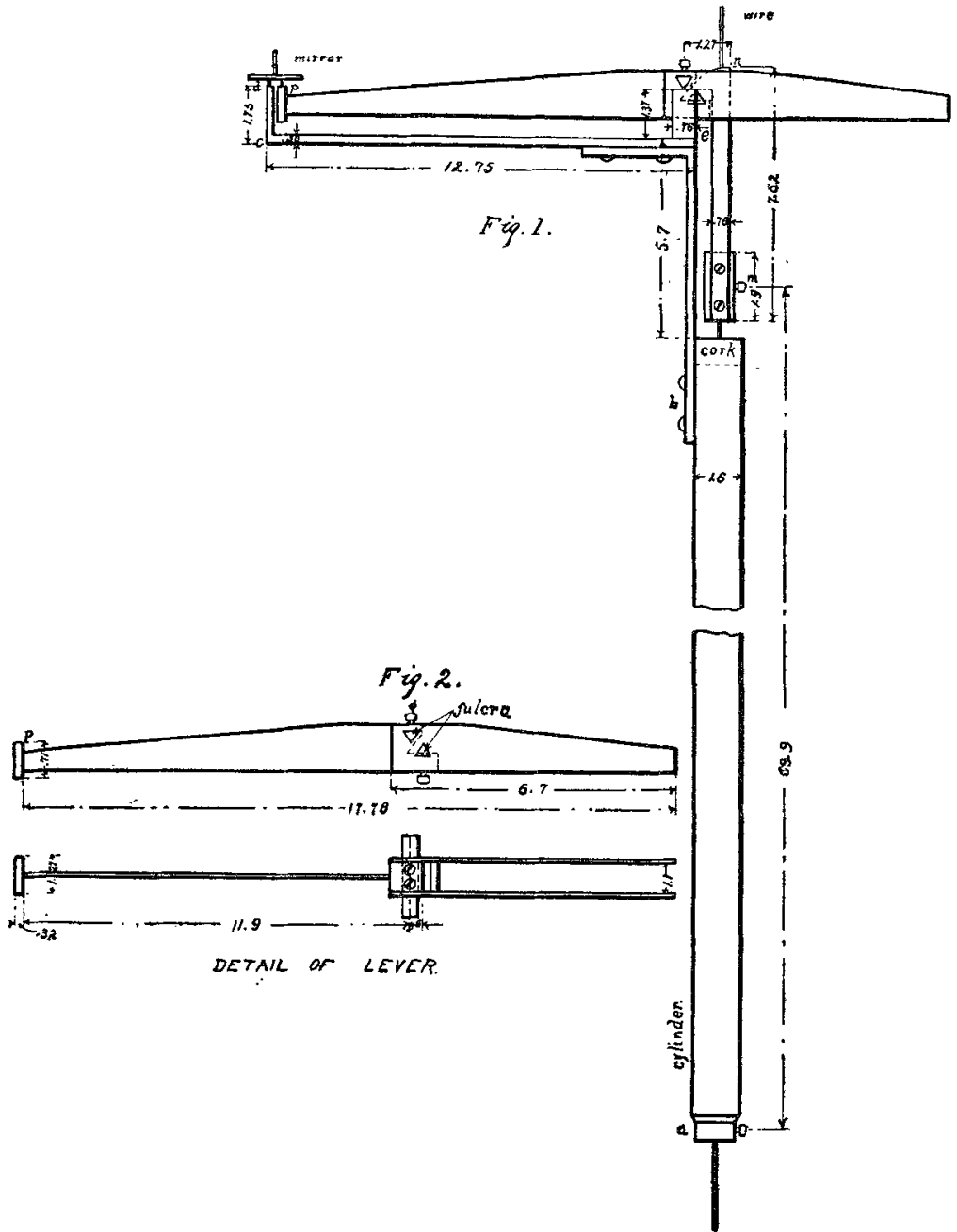

the wire at a point $a$, a short distance above the stone slab; a loosely fitting cork plug in its open upper end served to keep the wire in the axis of this cylinder. To the cylinder was screwed the brass arm $d e b$. At $e$ was screwed a hard 
steel support for the fulcrum of the lever. The side view of the support was of this shape $\longleftarrow$, the two projections supporting the knife-edge, and the body of the lever passing between them. To keep the lever horizontal and to register changes of length, another knife-edge with its blade upwards was embedded in the lever. This knife-edge pressed against the piece $m n$ which was screwed to the wire at $m$. Now if the points $m$ and $a$ were separated or brought closer together, the knife-edges would no longer remain in a horizontal line and the lever would tilt. The end $p$ of the lever, and the surface $d$ of the arm $b e d$ were made planes to support a small brass table, having on its upper face a vertical plane mirror, and for legs three short bits of needles, two of which stood on $p$ and one on $d$. By this arrangement the ehange in the length of $m a$ already magnified by the lever was much more apparent when the tilting of the mirror-table was read by means of a telescope and scale.

The most important dimensions are :-

$$
\begin{aligned}
& \text { Length of wire stretched, } m a \text {. . . } \quad \text {. } 69.9 \mathrm{~cm} \text {. } \\
& \text { Ratio of lever arms . . . . . . 119/4.65 } \\
& \text { Distance between needle-points . . . } 2 \cdot 3 \mathrm{~mm} \text {. } \\
& \text { " to telescope and scale . . } 1660^{\circ} 0 \text {, }
\end{aligned}
$$

The multiplying power of the apparatus was therefore

$$
\frac{119}{4 \cdot 65} \times \frac{1660}{2 \cdot 3} \times 2=36941 .
$$

And as the scale was graduated to millimetres, one scaledivision represented an actual change of length of $2.7 \times 10^{-5}$ millimetres.

The coil to magnetize the wire stood on the stone slab, and was long enough to reach just below the arm $c e$, so that the part of the wire $m a$ experimented on was in a practically uniform field.

The principal dimensions of this coil were as follows :-

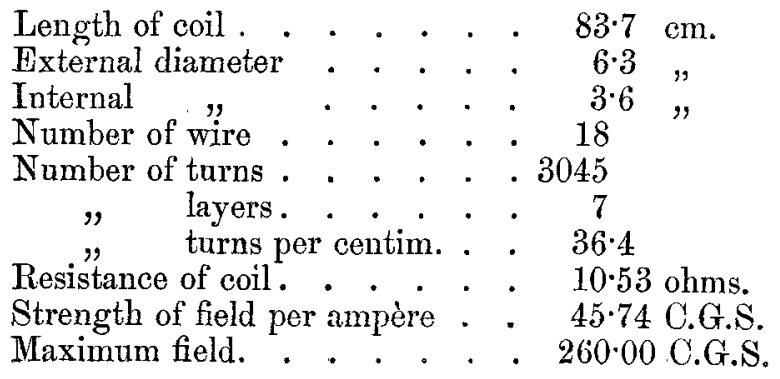


The core of this coil was made of two co-axal brass cylinders fastened together by the end plates of the coil. The space between these two cylinders was filled with water, which proved to be an excellent way of retarding the heat-effects produced by the current.

\section{Method.}

I at first intended to measure the elongation and the corresponding induction simultaneously, but found this difficult, and so adopted a more convenient and apparently as accurate a method. This was to first measure the current used to produce a given intensity of magnetism and the consequent changes in length, and afterwards to get the relation between the strength of field and the intensity of magnetism in the iron, the apparatus in the meanwhile remaining untouched. As the laboratory is situated in the city, the work had to be done late at night after traffic had stopped, for, in spite of all the precautions that could be thoughit of, the shaking of the apparatus could not be prevented. For this reason the induction was not determined immediately after obtaining the elongation-curve, but was done the next morning. The induction was measured by the method of reversals*. The induction-coil used for this purpose consisted of 200 turns of number $3 \dot{b}$ wire wonnd in one layer on a paper cylinder slightly greater in diameter than the specimen. This little cylinder was slipped over the wire and fixed halfway between $a \mathrm{~m}$. The galvanometer was calibrited by means of a standard coil having a wooden core. The secondary of the standard coil also consisted of 200 turns of wire, which plan saved much computation. The intensity was then calculated by the formula $\mathrm{B}=\mathrm{H}+4 \pi \mathrm{I}$. Knowing the change in length and the intensity of magnetization for any current, of course the relation between these two quantities could be easily plotted. The current was supplied by a battery of storage-cells, and the resistance was regulated by a slide-resistance of coppersulphate.

\section{Results.}

My first results were obtained from a specimen of moderately soft commercial iron wire, 1 millim, in diameter. This wire was free from stress except that due to the jacket-cylinder screwed to it, which weighed 350 grams. The elongations given (Table I.) are those due to temporary magnetism, and each value is the mean of two or three readings wbich did not

$$
\text { * Ewing, Iondon Electrician, April } 1894 .
$$

Plil. Mag. S. 5. Vol. 40. No. 245. Oct. 1895. 
vary by more than one per cent. The current was applied suddenly, and as soon as a reading was taken the contact was broken. This operation was then repeated, the current being increased each time, and readings taken until the maximum current was reached. By this means temperature-effects which are relatively slow to act were avoided.

Fig. 3.

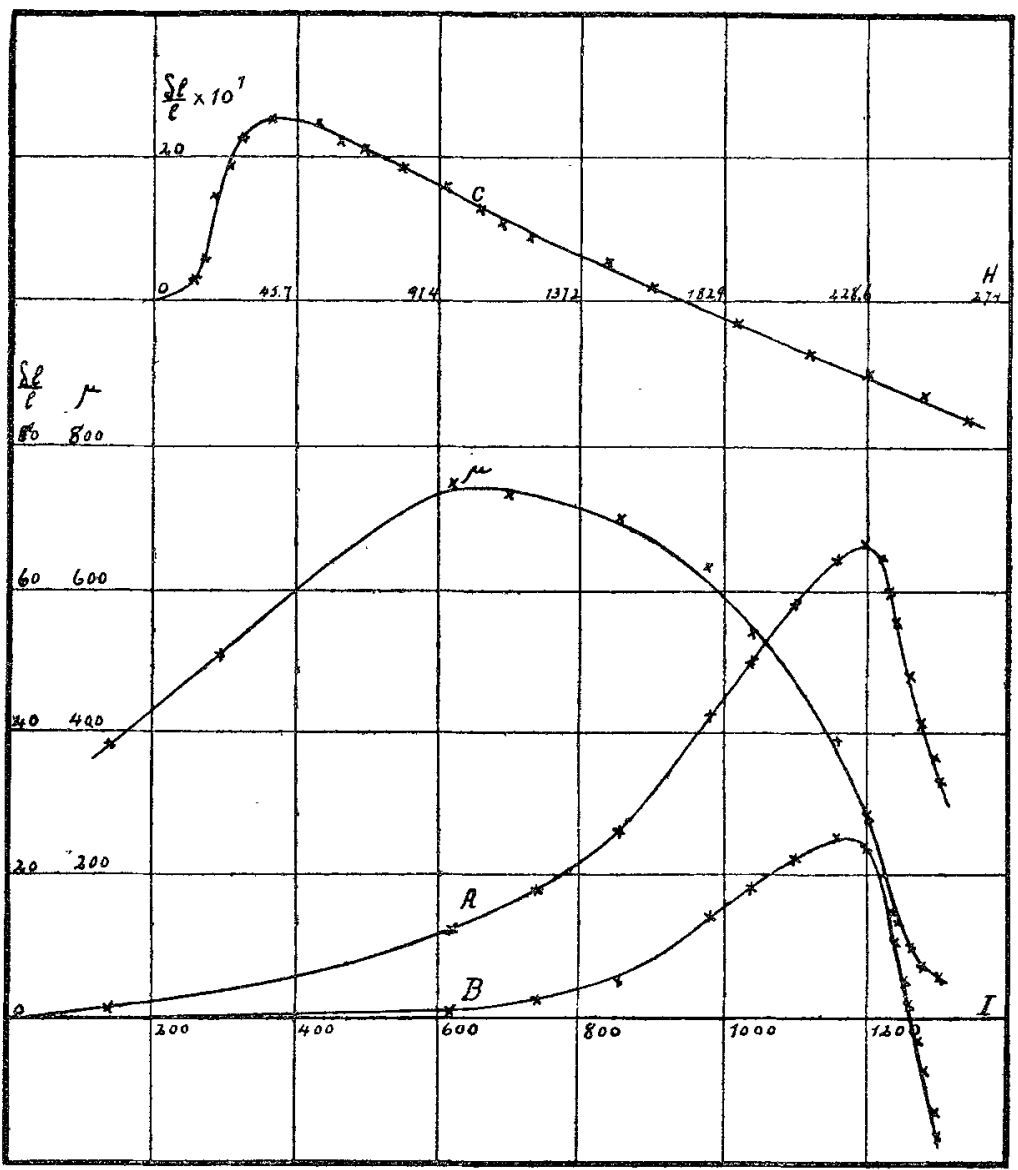

U.- Elongation and intensity of field.

B.-Elongation and magnetization.

A.-Do. corrected.

Fig. 3, C shows the relation between the elongation per unit length, $\frac{\delta l}{l} \times 10^{7}$, and the intensity of tne field, $\mathrm{H}$. This curve is seen to closely resemble in form those given by 
Shelford Bidwell. When the relation is expressed between change of length and intensity of magnetization, the curve takes the very different form given by fig. 3, B. The wire slowly increases in length until an intensity of about 800 is reached. From that point until a maximum length is attained, at an intensity of 1200 , the elongation is more marked. After reaching this maximum it rapidly contracts; the last portion of curve being approximately a nearly vertical straight line. The figure also shows that the point of maximum length does not correspond to the point of greatest permeability of the iron, as is seen by comparing this curve with the curve for permeability plotted on the same figure.

It is now necessary to make correction for the contraction due to the $\mathrm{B}^{2} / 8 \pi$ force. This contraction is obtained from the formula $\frac{\delta l}{l} \times 10^{7}=\frac{\mathrm{B}^{2} / 8 \pi}{\mathrm{M}}$, where $\mathrm{M}$ is the modulus of elasticity. My apparatus was well fitted for measuring the latter quantity. A weight of about five kilograms was hung on the wire and the elongations due to the additions of weights of 20,50 , and 100 grams were read. From these Young's Modulus was calculated in the ustral manner. It was found to be $2 \cdot 2 \times 10^{22}$ for the specimen used. The contractions dne to the $\mathrm{B}^{2} / 8 \pi$ force were then calculated and are given in column 6 of Table I.

Table I.

\begin{tabular}{|c|c|c|c|c|c|c|}
\hline H. & $\mu$. & I. & B. & $\frac{\partial l}{l}$ (obs.). & $\frac{\delta l}{l}\left(\frac{\mathrm{B}^{2}}{8 \pi}\right)$. & $\frac{\delta l}{l}(\operatorname{corr})$. \\
\hline $\begin{array}{l}4 \cdot 6 \\
7 \cdot 3\end{array}$ & $\begin{array}{l}384.8 \\
507.0\end{array}$ & $\begin{array}{l}141 \\
294\end{array}$ & $\begin{array}{l}1770 \\
3700\end{array}$ & $+0 \cdot 10$ & -0.7 & $+0 \cdot 80$ \\
\hline $10 \%$ & $\begin{array}{r}5060 \\
7524\end{array}$ & 633 & 7900 & $1 \cdot 16$ & $11 \cdot 3$ & 1246 \\
\hline 11.8 & 7330 & 700 & 8800 & & & \\
\hline $12 \cdot 8$ & $726 \%$ & 739 & 9300 & 271 & 1565 & 1833 \\
\hline 15.5 & 6950 & 856 & 10770 & 5.71 & 20.98 & $26 \cdot 69$ \\
\hline $9 \cdot 7$ & 6270 & 981 & 12350 & 14.71 & $27 \cdot 60$ & 4231 \\
\hline $24 \cdot 2$ & $541 \cdot 4$ & $104 \mathrm{l}$ & 13100 & $18 \cdot 78$ & $31 \cdot 05$ & 4983 \\
\hline 28.8 & 48.7 & 104 & 13900 & 22.92 & 3495 & 57.87 \\
\hline $37 \cdot 6$ & $389 \cdot 1$ & 1163 & 14630 & 2555 & 38.53 & $64 \cdot 13$ \\
\hline 53.0 & $286^{\circ} 3$ & 1203 & 15170 & 2478 & $41 \cdot 69$ & 60.47 \\
\hline 604 & 2,37 & 1214 & 15320 & 23.23 & 42.47 & 6570 \\
\hline 67.7 & $227 \cdot 7$ & 1222 & 15410 & $21 \cdot 30$ & 4296 & 64.26 \\
\hline $80 \div$ & 1938 & 1228 & 15500 & 1874 & $43 \cdot 16$ & 6220 \\
\hline 93.3 & 167.2 & 1235 & 15600 & 15.49 & 44.02 & $59 \cdot 51$ \\
\hline 1038 & 150.8 & 1238 & 15650 & 12.81 & 4430 & $57 \cdot 11$ \\
\hline 111.6 & $140 \cdot 7$ & 1241 & 15700 & 11.03 & $44 \div 59$ & 5562 \\
\hline 121.2 & 130.0 & 1244 & 15750 & $9 \cdot 20$ & $44 \cdot 88$ & 54.08 \\
\hline 145.4 & 1096 & 1257 & 15930 & 5.42 & 45.90 & $51 \cdot 32$ \\
\hline $159 \cdot 1$ & $100 \cdot 6$ & 1261 & 16010 & +1.94 & 4637 & $48 \% 31$ \\
\hline 18655 & 86.9 & 1274 & 16200 & -291 & $47 \cdot 47$ & 44.53 \\
\hline 210.3 & 77.8 & 1281 & 16360 & 697 & 48.42 & $41 \cdot 45$ \\
\hline 2469 & $67 \cdot 1$ & 1299 & 16570 & 1297 & $49 \cdot 67$ & 3670 \\
\hline 260.5 & 639 & 1304 & 16650 & 16.65 & $50 \cdot 15$ & 8330 \\
\hline
\end{tabular}

$2 \mathrm{~B} 2$ 
The last column of this table was found by taking the difference between the observed elongation and the $\mathrm{B}^{2} / 8 \pi$ contraction. The relation between this corrected elongation, due to what has been called the direct action of the magnetism, and the intensity of magnetization is graphically shown by fig. 3, A. The effect of this correction is to make the elongation much greater for a given intensity. The maximum value of the elongation is more than twice as great as the observed maximum. And the greatest intensity employed, 1300 C.G.S. units, produces an elongation and not a contraction as observed.

No correction for the change in elasticity was made. For the present case it would be insignificant. See diseussion of errors at end of this paper.

\section{Effect of Hardening.}

The effect of hardening the wire was next considered. A piece of the same quality of iron was heated to a bright red by passing a current through it, and then suddenly cooled. After the operation the wire was much harder and only slightly burnt on the surface. The observed changes in length, those due to $\mathrm{B}^{2} / 8 \pi$, and the corrected ralues are given in Table II.

TABLE II.

\begin{tabular}{|c|c|c|c|c|c|}
\hline H. & I. & B. & $\frac{\delta l}{l}$ (obs.). & $\frac{\delta l}{l}\left(\frac{\mathrm{B}^{2}}{8 \pi}\right)$ & $\frac{\delta l}{\bar{l}}(\operatorname{corr})$ \\
\hline $5 \cdot 0$ & 8 & 100 & -0.00 & -0.00 & +0.00 \\
\hline 87 & 53 & 670 & 0.05 & 0.08 & 0.03 \\
\hline $12 \cdot 8$ & 272 & 3420 & $0 \cdot 10$ & $2 \cdot 12$ & $2 \cdot 02$ \\
\hline $18 \cdot 3$ & 709 & 8920 & $0 \cdot 20$ & $14 \cdot 41$ & $14 \cdot 21$ \\
\hline $27 \cdot 4$ & 923 & 11620 & 0.50 & $24 \cdot 44$ & 2394 \\
\hline 366 & 947 & 11940 & 0.70 & $25 \cdot 77$ & 2507 \\
\hline $45 \cdot 7$ & 1012 & 12770 & 1.85 & $29 \cdot 48$ & $27 \cdot 63$ \\
\hline $57 \cdot 2$ & 1044 & 13180 & $3 \cdot 10$ & 31.42 & $28 \cdot 32$ \\
\hline 68.5 & 1060 & 13300 & $4 \cdot 10$ & $32 \cdot 42$ & 28.32 \\
\hline 96.5 & 1074 & 13600 & $7 \cdot 40$ & $33 \cdot 43$ & 26.03 \\
\hline $118 \cdot 8$ & 1064 & 13490 & 540 & 32.93 & $27 \cdot 53$ \\
\hline $138 \cdot 5$ & 1100 & 13560 & (?) 15.00 & $35 \cdot 24$ & $20 \cdot 24$ \\
\hline $180 \cdot 1$ & 1126 & 14320 & $24 \cdot 20$ & $37 \cdot 11$ & $12 \cdot 91$ \\
\hline
\end{tabular}

Hardening the iron makes the elongation smaller, and for the prosent specimen, the least intensity of magnetization caused the wire to contract (fig. 4, B). The corrected relation between the cbange of length and the intensity is shown by fig. 4, B'. On this figure is also plotted curve A, the same relation, taken from fig. 3 , for the wire when not hardened, and curve $A^{\prime}$ shows the corrected relations for the same. 
Although the observed change for the hardened wire was a contraction, the contraction due to the $\mathrm{B}^{2} / 8 \pi$ force was sufficient to bring the values above the zero axis. So, again, the

Fig. 4 .

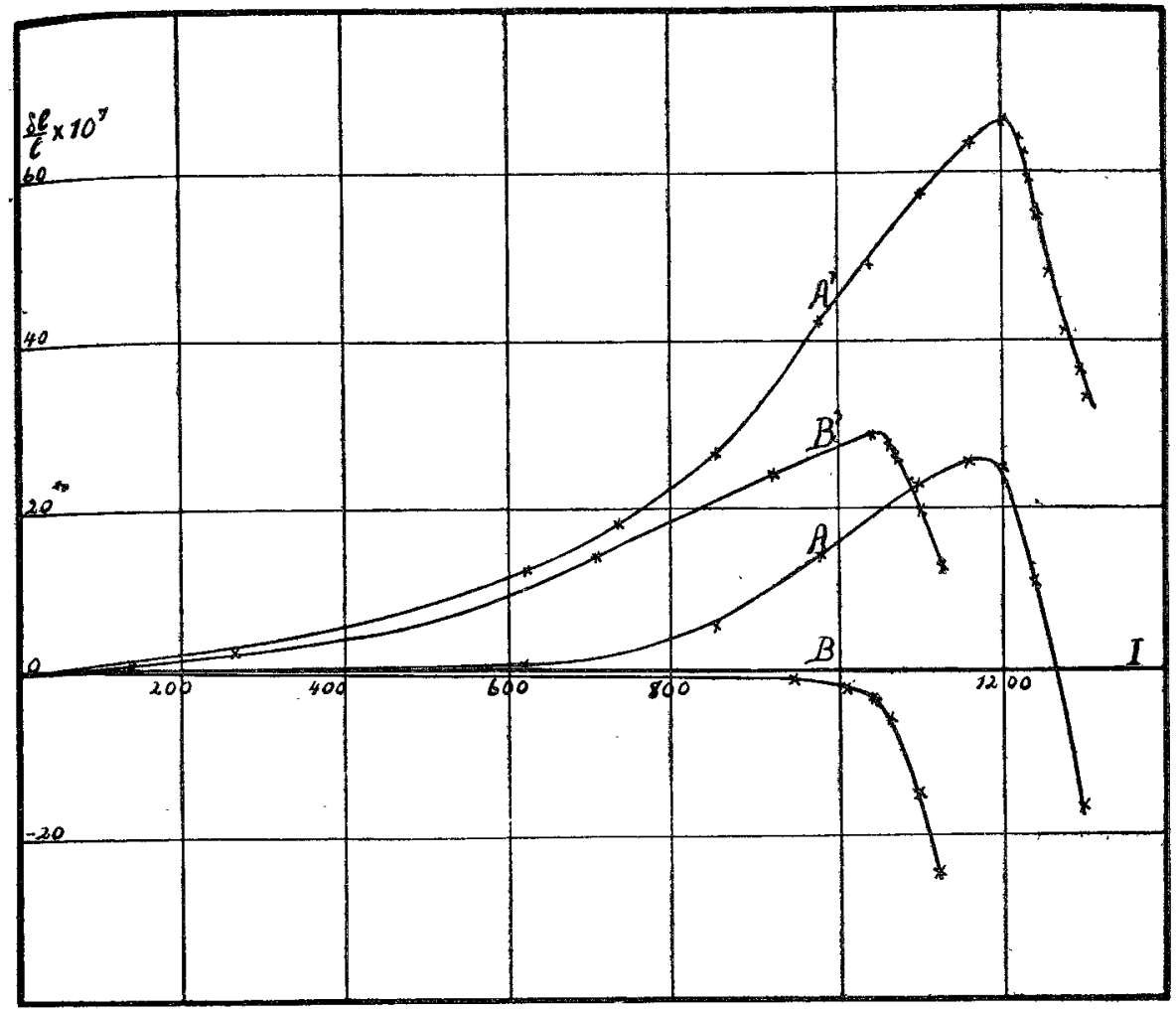
A.-Wire natural.
A'.-Do, corrected.
B. - Wire hardened.
B'.-Do. corrected.

direct action of the magnetization is to elongate the wire. The corrected curve is very similar to the curve for the iron in its original state. The absolute values are, however, much diminished and the maximum occurs, for the specimen, with a less intensity. The correction for the change of elasticity can be neglected as in the first case.

\section{Effect of Strain.}

To find the effect of strain the wire was loaded with a weight of 750 kilog. per square centimetre, and the relation 
between the elongation and the intensity of magnetization obtained as in the previous cases. The wire was then loaded with a weight of 1750 kilog. per square centimetre and the same relations found. The values are given in Tables III. and IV. The effects of strains are also shown graphically by fig. 5, for the observed and corrected value. On consulting the figure, it is seen that straining the wire produces the the same change that hardening it does. The values are reduced, and the maximum points oceur with less intense magnetization. The curves in this figure, as well as in the two former figures, marked no load, have an inaccuracy due to the strain caused by the weight of the jacket cylinder, and should have ordinates a trifle greater.

Although the change in elasticity has hitherto produced little effect, as soon as the wire is much strained this correction becomes very important and will modify the curves materially. This alteration in the curves it has not been possible to make, as the relation between the change in elasticity and the intensity of magnetization is unknown. However, from Bock's results some approsimations may be arrived at, and these will be considered when the errors likely to ocenr in this investigation are discussed.

TABLE III.

\begin{tabular}{|c|c|c|c|c|c|}
\hline H. & I. & B. & $\frac{\delta l}{l}$ (obs.). & $\frac{\delta l}{l}\left(\frac{\mathrm{B}^{2}}{8 \pi}\right)$. & $\frac{\delta l}{l}$ (corr.). \\
\hline 69 & 636 & 8000 & +0.12 & -11.58 & +1170 \\
\hline $11 \cdot 4$ & 918 & 11550 & $0 \cdot 62$ & $24 \cdot 14$ & 2476 \\
\hline $18 \cdot 5$ & 1080 & 13600 & 263 & $33 \cdot 46$ & 36.09 \\
\hline 242 & 1109 & 13960 & $3 \% 3$ & 35.27 & 39.00 \\
\hline $30 \cdot 2$ & $11 \leqq 9$ & 14340 & $3 \cdot 87$ & $37 \cdot 19$ & 41.06 \\
\hline $34 \cdot 7$ & 1150 & 14480 & 3.48 & 37.94 & 41.42 \\
\hline 439 & 1167 & 14700 & $2 \cdot 42$ & 3909 & $41 \cdot 51$ \\
\hline 558 & .1184 & 14930 & $+1 \cdot 20$ & $40 \cdot 33$ & 41.53 \\
\hline 732 & 1204 & 15200 & -039 & 4179 & $41 \cdot 40$ \\
\hline 81.8 & 1212 & 15300 & $1 \cdot 16$ & $42 \cdot 35$ & $41 \cdot 19$ \\
\hline 1006 & 1223 & 15470 & $4: 41$ & $43 \cdot 30$ & 38.89 \\
\hline 1225 & 1235 & 15640 & $9 \cdot 10$ & $44 \cdot 24$ & $35 \cdot 14$ \\
\hline $148 \cdot 1$ & 1247 & 15820 & $14 \cdot 13$ & $45 \cdot 27$ & $31 \cdot 11$ \\
\hline 157.7 & 1253 & 15910 & 1580 & 45.80 & 3000 \\
\hline $175 \cdot 1$ & 1265 & 16070 & 18.58 & 46.71 & $28 \cdot 13$ \\
\hline $192 \cdot 1$ & 1276 & 16230 & $25 \cdot 05$ & $47 \cdot 65$ & $22 \cdot 60$ \\
\hline $298 \cdot 6$ & 1287 & 16400 & $29 \cdot 03$ & 48.65 & 19.62 \\
\hline $251 \cdot 1$ & 1293 & 16500 & $32 \cdot 13$ & $49 \cdot 26$ & $17 \cdot 1 \overline{3}$ \\
\hline
\end{tabular}


produced in Iron Wires by Magnetization.

TABLE IV.

\begin{tabular}{|c|c|c|c|c|c|}
\hline H. & I. & B. & $\frac{\partial l}{l}$ (obs.). & $\frac{\delta l}{l}\left(\frac{\mathbf{B}^{2}}{8 \pi}\right)$. & $\frac{\delta l}{l}$ (corr.). \\
\hline 5.5 & 581 & 7300 & -0.19 & $-9 \cdot 64$ & +9.54 \\
\hline $9 \cdot 1$ & 922 & 11600 & 0.58 & $24 \cdot 35$ & $\begin{array}{l}T \\
23.77\end{array}$ \\
\hline 13.7 & 1011 & 12720 & $1 \cdot 26$ & $29 \cdot 27$ & 28.01 \\
\hline $21 \cdot 5$ & 1070 & 13470 & 2.90 & 3283 & 29.93 \\
\hline $27 \cdot 4$ & 1100 & 13860 & 4.06 & 34.76 & 30.70 \\
\hline $36 \cdot 6$ & 1134 & 14280 & 590 & 36.89 & 30.99 \\
\hline $45 \cdot 7$ & 1155 & 14560 & $7 \cdot 36$ & 38.36 & $31 \cdot 00$ \\
\hline 54.9 & 1167 & 14710 & 968 & $39 \cdot 14$ & $29 \cdot 46$ \\
\hline 73.2 & 1178 & 14880 & 13.84 & 40.05 & 26.21 \\
\hline 86.9 & 1186 & 14990 & $16 \cdot 64$ & $40 \cdot 65$ & 24.01 \\
\hline 960 & 1190 & 15050 & 19.74 & 40.97 & 21.23 \\
\hline $111 \cdot 1$ & 1198 & 15160 & $23 \cdot 63$ & 41.58 & $17 \cdot 95$ \\
\hline 128.0 & 1207 & 15290 & 27.87 & $42 \cdot 29$ & $14 \cdot 42$ \\
\hline $139 \cdot 4$ & 1212 & 15370 & 32.51 & 42.74 & 10.23 \\
\hline 150.9 & 1217 & 15440 & 33.97 & $43 \cdot 12$ & $9 \cdot 15$ \\
\hline
\end{tabular}

Fig. 5 .

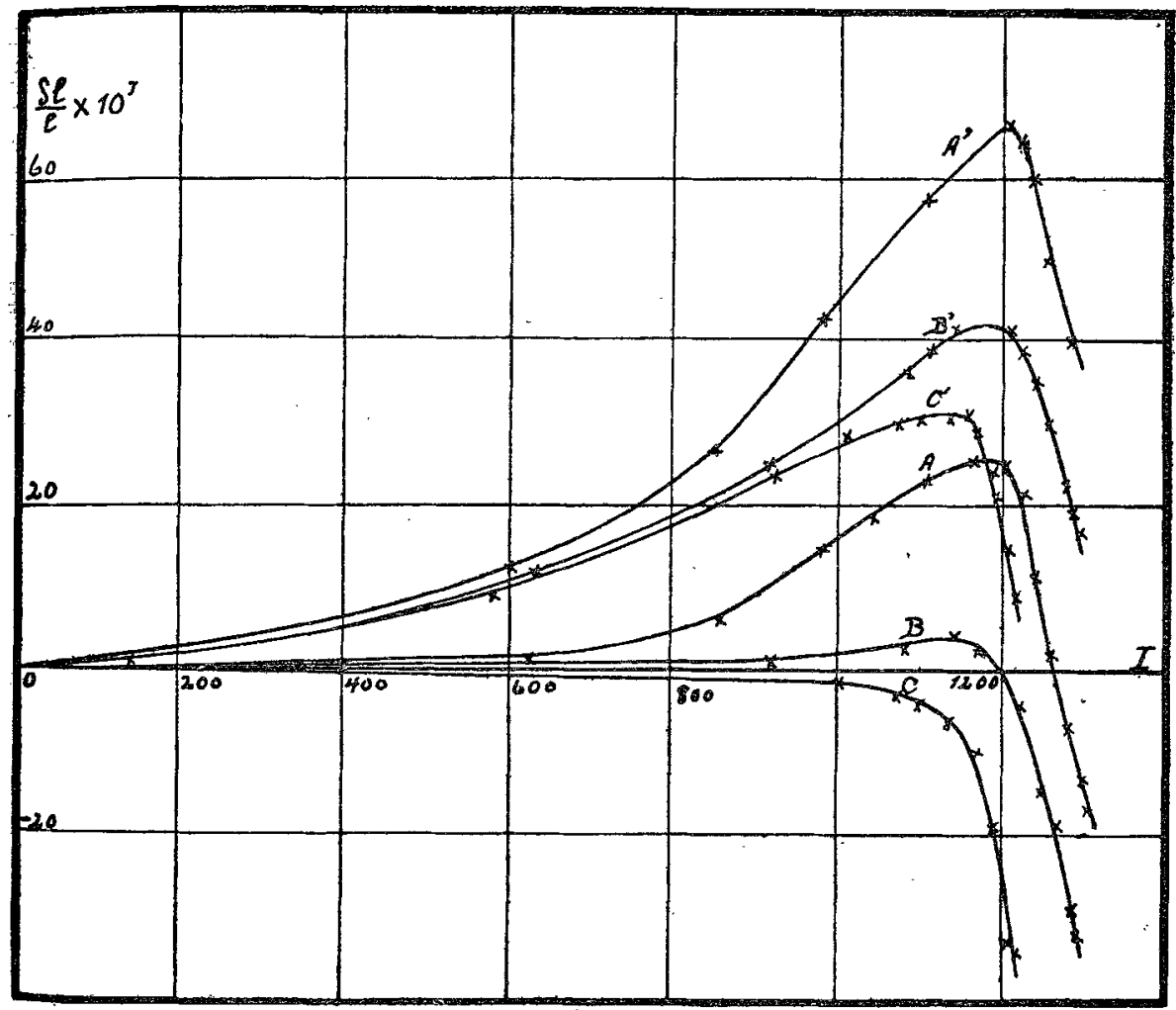

A.- No load. $\quad$ B. $-750 \mathrm{kgs}$. per' sq. centim. C. $-1750 \mathrm{kgs.}$ per sq. cm.

A'.-Do corrected. B'.-Do. corrueted. $\quad$ O'. $^{\prime}$-Do. corrected. 


\section{Possible Errors.}

It has been shown that the change in elasticity occurring when an iron wire is magnetized will modify the relation between the intensity of magnetization and the elongation, and it has been assumed that, except for heavily loaded wires, this effect will be very small. Bock* found as a result of his experinents that magnetizing soft iron made it more incompressible, and that the change in elastieity was less than one half per cent. He could not find any relation between the intensity of magnetization and change in elasticity, so that it is impossible to give more than a probable maximum to the correction it is necessary to make in the curves given in this investigation.

If we take $B=20,000$,

and

$$
\frac{B^{2}}{8 \pi}=\frac{1}{2 \pi} \times 10^{8} \text { dynes per square centimetre, }
$$

$$
\frac{\delta l}{l} \times 10^{7}=-\frac{\frac{1}{2 \pi} \times 10^{8}}{\bar{M}}=-73 .
$$

A change of $\frac{1}{2}$ per cent. in $\frac{\delta l}{l}$ would give a correction of $.005 \times 73=\cdot 4$ of a unit. This correction may therefore be neglected, as errors greater than this would occur in measuring $\mathrm{B}$.

It was also assumed that when the wire was not stretched except by the jacket, the correction might be neglected.

The weight of this was 350 grams or 42,000 dynes per square centimetre, then

$$
\frac{\delta l}{l} \times 10^{7}=\frac{42000}{\mathrm{M}} \times 10^{7}=200 .
$$

A change of $\frac{1}{2}$ per cent. in 200 is $1^{\circ} 0$. Consequently the curves marked no load are not significantly changed by making this correction.

But when we consider the case of the wire loaded with 750 kilograms per square centimetre, we get, by similar calculation, a correction of 15 units ; and for the wire under the greatest tension, 1750 kilograms per square centimetre, a correction of 40 units. Since the magnetism makes the metal more incompressible, this correction enters as a contraction

* Buck, loc. cit. 
and must be added to the ordinates of the curves plotted on fig. 5. It is impossible to say how these curves would be affected by the correction, but probably the correction increases with the intensity of magnetization.

Changes in the length of the wire due to variations in temperature are another possible source of error. These changes take place more slowly than the elongation produced by the magnetization, so that the two effects may be separated. To retard them still more the core of the solenoid was made of two co-axal cylinders and the space between them filled with water. With this arrangement the current could be applied, the reading taken, and the current shut off before the gradual change of the zero point due to the heating of the wire by the current could be observed. Changes in the temperature of the room when they did occur were too slow to noticeably affect the results.

\section{Summary.}

The following is a summary of the results obtained by this investigation :-

1. A relation has been obtained between the elongation due to magnetization and the intensity of magnetization of soft iron. When the elongation has been corrected for the contraction caused by the $\mathrm{B}^{2} / 8 \pi$ force, the relation may be expressed thus :-A rod of iron elongates slowly until an intensity of about 800 is reached. After that point the rod elongates more rapidly and attains a maximum value of about $60 \times 10^{-7}$ part of its length at an intensity of 1200 . With greater intensities the elongation diminishes, the curve being approximately a nearly vertical straight line.

2. Hardening the wire diminishes the correcied elongation, and the wire attains its maximum length in a less intense field.

3. It has been shown that when the wire is stretched, the change in elasticity due to the magnetization produces an important effect. Neglecting this correction, the effects of stretching are similar to those caused by hardening the wire.

Before concluding I would acknowledge my indebtedness to Professor Rowland, not only for suggesting the investigation to me, but also for his assistance and kind consideration afterwards.

I also owe many thanks to Dr. Ames and to Dr. Duncan for advice and help. 